\title{
EFEITO DE NÍVEIS DE SILÍCIO NA ÁGUA DE BEBIDA SOBRE O DESEMPENHO, RENDIMENTO DE CARCAÇA, EXCREÇÃO DE MINERAIS E PERFIL DE ÁCIDOS GRAXOS NO MÚSCULO PEITORAL DE FRANGOS DE CORTE
}

\author{
EFFECT OF LEVELS OF SILICON IN DRINK WATER OF BROILER ON PERFORMANCE, \\ CARCASS YIELD, EXCRETION OF MINERALS AND FATTY ACID PROFILE
}

\author{
S. SGA VIOLI ${ }^{1 *}$, M. F. F. M. PRAES ${ }^{1}$, C. H. F. DOMINGUES ${ }^{1}$, D. C. CASTIBLANCO ${ }^{1}$, \\ S. M. BARALDI-ARTONI ${ }^{1}$, O. M. JUNQUEIRA ${ }^{2}$
}

\begin{abstract}
RESUMO
O objetivo do estudo foi avaliar o efeito de níveis de silício na água de bebida de frangos de corte sobre o desempenho, o rendimento de carcaça, o metabolismo do cálcio, fósforo e nitrogênio e o perfil de ácidos graxos no músculo peitoral de frangos de corte. Foram utilizadas 1.120 pintos machos de um dia de idade da linhagem Cobb, distribuídas em um delineamento inteiramente casualisado, com quatro níveis de silício na água de bebida $(0 ; 0,5 \mathrm{mg} ; 1,0 \mathrm{mg}$ e $1,5 \mathrm{mg}$ do produto/100 kg de peso/dia), totalizando quatro tratamentos com oito repetições e 35 aves por parcela. A análise estatística dos dados foi realizada pelo método da análise de variância com o auxílio do procedimento GLM do SASß e em caso de significância, os níveis de inclusão de silício foram estimados por intermédio dos modelos de regressão polinomial. A suplementação de silício via água de bebida promoveu efeito quadrático sobre a coxa+sobrecoxa com valor máximo de rendimento estimado em 28,87\%. Com relação aos perfis de ácidos graxos observou - se efeito linear para os ácidos graxos vacênico, $\gamma$-linolênico, araquidico e palmítico e efeito quadrático para os ácidos graxos mirístico, miristoleico, palmitoleico e eicosadienoico. O silício modificou o perfil de ácidos graxos no músculo peitoral, bem como o rendimento de coxa+sobrecoxa das aves aos 49 dias de idade, podendo ser uma ferramenta importante a ser utilizada para a nutrição das aves.
\end{abstract}

PALAVRAS-CHAVE: Conversão alimentar. Ganho de peso. Metabolismo. Rendimento de carcaça.

\section{SUMMARY}

The aim of this study was evaluate different levels of silicon in the drinking water of broilers on performance, carcass yield, metabolism of calcium, phosphorus and nitrogen and fatty acid profiles of pectoral muscle of broilers. A total of 1,120 one-day-old male Cobb chicks were used, distributed in a completely randomized design within four levels of silicon in the drinking water $(0,0.5 \mathrm{mg}, 1.0 \mathrm{mg}$ and $1.5 \mathrm{mg}$ of silicon/100 kg/day), and eight replicates of 35 birds each . The data were analysed by the PROC GLM procedure of SAS ${ }^{\circledR}$ and in case of significance polynomial regressions were performed. Silicon supplementation in the drinking water promoted quadratic effect on thigh and drumstick with maximum yield estimated of $28.87 \%$. For fatty acid profiles were observed linear effect for $\gamma$ - linolenic, vaccenic, arachidonic and palmitic, and quadratic effect for myristic, myristoleic, palmitoleic and eicosadienoic. Silicon modified the fatty acid profiles of pectoral muscle as well as yield of thigh and drumstick of 49 days old birds, and could be an important tool to be used for poultry nutrition.

KEY-WORDS: Carcass yield. Feed Conversion. Weight gain. Metabolism.

\footnotetext{
${ }^{1}$ Universidade Estadual Paulista Júlio de Mesquita Filho, Jaboticabal, SP, Brasil.

${ }^{2}$ Universidade Federal de Goiás, Jataí, GO, Brasil.
} 


\section{INTRODUÇ̃̃O}

O silício $(\mathrm{Si})$ é um mineral importante para a formação de ossos e do colágeno dos tecidos conjuntivos (CARLISLE, 1981), sendo fundamental, inclusive, também, para a absorção de cálcio, nos estágios iniciais da formação óssea. Além de fazer parte integrante de estruturas conjuntivas, tem também função moduladora sobre diversas vias metabólicas fundamentais para a homeostase do organismo, especialmente a dérmica, tendo, portanto, papel fundamental no desempenho de frangos de corte (CARLISLE, 1972; ELLIOT, 1980).

Em experimentos realizados com frangos de corte (CARLISLE, 1972; ELLIOT 1980; CARLISLE, 1981), os resultados demonstram que o Si desempenha papel fisiológico importante nas aves e os autores afirmam a sua essencialidade na formação óssea. No entanto, são poucos os trabalhos com $\mathrm{Si}$, muitas vezes subestimando-se a participação deste elemento dentro da biologia animal. Portanto, tornam-se importante, informações sobre o efeito do silício sobre os parâmetros zootécnicos na criação de frangos de corte, e os aspectos nutricionais desse elemento.

Sendo que pouco se sabe sobre o efeito do silício quando adicionado a água de bebida de frangos de corte, buscou-se avaliar a ação do mesmo sobre diferentes características de valor zootécnico e fisiológico. Dentro do contexto exposto, o presente estudo teve como objetivo avaliar o efeito de níveis de silício na água de bebida de frangos de corte sobre o desempenho, o rendimento de carcaça, o metabolismo do cálcio, fósforo e nitrogênio e o e o perfil de ácidos graxos no músculo peitoral de frangos de corte.

\section{MATERIAL E MÉTODOS}

\section{Aves, manejo e delineamento experimental}

Utilizaram-se 1.120 pintos machos de um dia de idade da linhagem $\mathrm{Cobb}^{\circledR}$, em um galpão constituído de 32 parcelas (boxes), resultando em 35 aves por parcela, distribuídas em um delineamento inteiramente casualisado, com quatro níveis de inclusão de silício (0; $0,5 \mathrm{mg} ; 1,0 \mathrm{mg}$ e $1,5 \mathrm{mg}$ de produto/100 $\mathrm{kg}$ de peso/dia). O produto comercial utilizado continha a composição de $30 \mathrm{~g}$ de silício em um litro de solução. Os pintos foram criados do $1^{\circ}$ ao $49^{\circ}$ dia de idade. Durante todo o período experimental as aves receberam água e ração à vontade, e foram mantidas sob conforto térmico através do manejo de cortinas e campânulas. Os pintos foram vacinados no incubatório contra as doenças de Marek e Bouba Aviária, e durante o período experimental adotou-se o seguinte programa de vacinação: $7^{\circ}$ dia de idade contra Gumboro (cepa fraca) via ocular e no $14^{\circ}$ dia de idade vacinação contra New Castle e Gumboro (cepa forte) via água de bebida, sendo utilizado leite em pó como veículo $\left(2 \mathrm{~g} \mathrm{~L}^{-1}\right)$.

Durante todo experimento, foram registradas diariamente as temperaturas e umidade relativa no interior do galpão, utilizando-se dois termo-higrômetros digitais localizados em pontos equidistantes do galpão na altura das aves. Para a média das máximas, mínimas e máximas e mínimas absolutas, os valores de temperatura e umidade relativa foram 30.00, 18.60, 34.10 e $13.40^{\circ} \mathrm{C}$ e $73,36,36,18 \% .27,82$ e $15,00^{\circ} \mathrm{C}$ e 59,25 e $37,09 \%$.

As rações foram preparadas à base de milho e farelo de soja (Tabela 1), reajustadas para as fases de criação (1 a 21 dias), de crescimento (22 a 42 dias de idade) e final (43 a 49 dias de idade) atendendo as recomendações de Rostagno et al. (2005).

\section{Desempenho}

Ao final do período experimental (49 dias de idade) realizou-se o controle do ganho de peso, consumo de ração, conversão alimentar, peso médio e viabilidade criatória.

\section{Características de carcaça e gordura abdominal}

Aos 49 dias de idade foram retiradas, ao acaso, quatro aves por boxe, sendo 32 aves por tratamento, totalizando 128 aves, utilizando-se como critério de escolha, as aves que apresentaram o peso corporal próximo ao peso médio da respectiva parcela.

As aves foram identificadas individualmente por anilhas numeradas no $49^{\circ} \mathrm{dia}$, e passaram por um período de oito horas de jejum, e foram eutanasiadas por deslocamento cervical seguido de sangria da jugular, para que o óbito tenha ocorrido por hipovolemia, depenadas, evisceradas e após pesagem das carcaças, foram submetidas a cortes para avaliação do rendimento de carcaça (desconsiderando cabeça e pés) e rendimento de cortes (peito, coxa + sobrecoxa, asa + sobreasa e dorso), além de utilizar o método da colheita total da cavidade abdominal para retirar a gordura. Para o cálculo de rendimento de carcaça, de cortes de gordura abdominal, tomou-se como base o peso individual de cada ave, o qual foi obtido imediatamente antes do abate. O abate está em acordo com o conselho de comissão de ética de uso de animais, aprovado dia 13 de março de 2013, tendo o certificado com o numero de protocolo 004742/13.

\section{Perfil de ácidos graxos no peito}

No $49^{\circ}$ dia de idade durante o abate descrito acima, foram colhidas amostras de $10 \mathrm{~g} \pm \mathrm{g}$ do músculo peitoral maior extraído de quatro aves/tratamento para a análise do perfil de ácidos graxos, totalizando 16 amostras. As analises foram realizadas no laboratório de Tecnologia da UNESP - Jaboticabal.

A metodologia adotada quanto à extração e à esterificação dos lipídeos foi a descrita por Hulan et al. (1989). Após a obtenção dos ésteres, estes foram analisados em um cromatógrafo gasoso GC-17A Shimadzu, dotado de detector de ionização em chama de injeção manual, coluna capilar (CARBOVAX), sendo utilizado $\mathrm{H}_{2}$ como gás de arraste. Os cálculos foram feitos por integração com um computador ligado ao detector. Os picos dos ácidos graxos foram identificados pela comparação com um padrão de composição conhecida.

Foram utilizados no total 21 padrões de ácidos graxos: monoinsaturados, poliinsaturados, insaturados e saturados. Monoinsaturado $=$ araquidico $(\mathrm{C} 20: 0)$, 
eicosenoico (C20:1n9), miristoleico (C14:1), palmitoleico (C16:1), heptadecenoico (C17:1), oléico (C18:1n9c), vacênico $(\mathrm{C} 18: 1 \mathrm{n} 7 \mathrm{c})$; poliinsaturado $=$ linoleico (C18:2n6c), y-linolênico (C18:3n6), $\alpha$-linolênico (C18:3n3), eicosadienoico (C20:2), eicosatrienoico (C20:3n6), eicosatrienoico (C20:3n3), araquidônio (C20:4n6), docosahexaenoico (C22:6n3); insaturado = eicosapentaenoico (C20:5n3); saturado = mirístico (C14:0), palmítico (C16:0), heptadecanoico (C17:0), esteárico (C18:0), pentadecanoico (C15:0).

\section{Ensaio de metabolismo}

Com 35 dias de idade das aves, foi realizado um ensaio de metabolismo para verificar a biodisponibilidade do fósforo, cálcio e nitrogênio nas excretas de frangos de corte machos submetidos aos tratamentos já descritos. Foi mantido o mesmo delineamento experimental, contudo, com quatro repetições por tratamento, com quatro aves cada/repetição, totalizando 64 aves.

Em todas as parcelas foram retiradas quatro aves, no entanto, somente foram utilizadas as aves necessárias para o ensaio de metabolismo, as demais aves foram alojadas em boxes restantes dentro do barracão. Com relação ao desempenho zootécnico, estas aves foram contabilizadas como mortas, no entanto, esta mortalidade não foi utilizada para os cálculos de viabilidade criatória, não ocasionando, portanto, em diferenças dos dados de desempenho. $\mathrm{O}$ abate foi realizado após a pesagem das aves, e, portanto, também não ocasionou em perda para a parte de desempenho.

Tabela 1 - Composição percentual e nutricional calculada da ração para as diferentes fases nutricionais de frangos de corte.

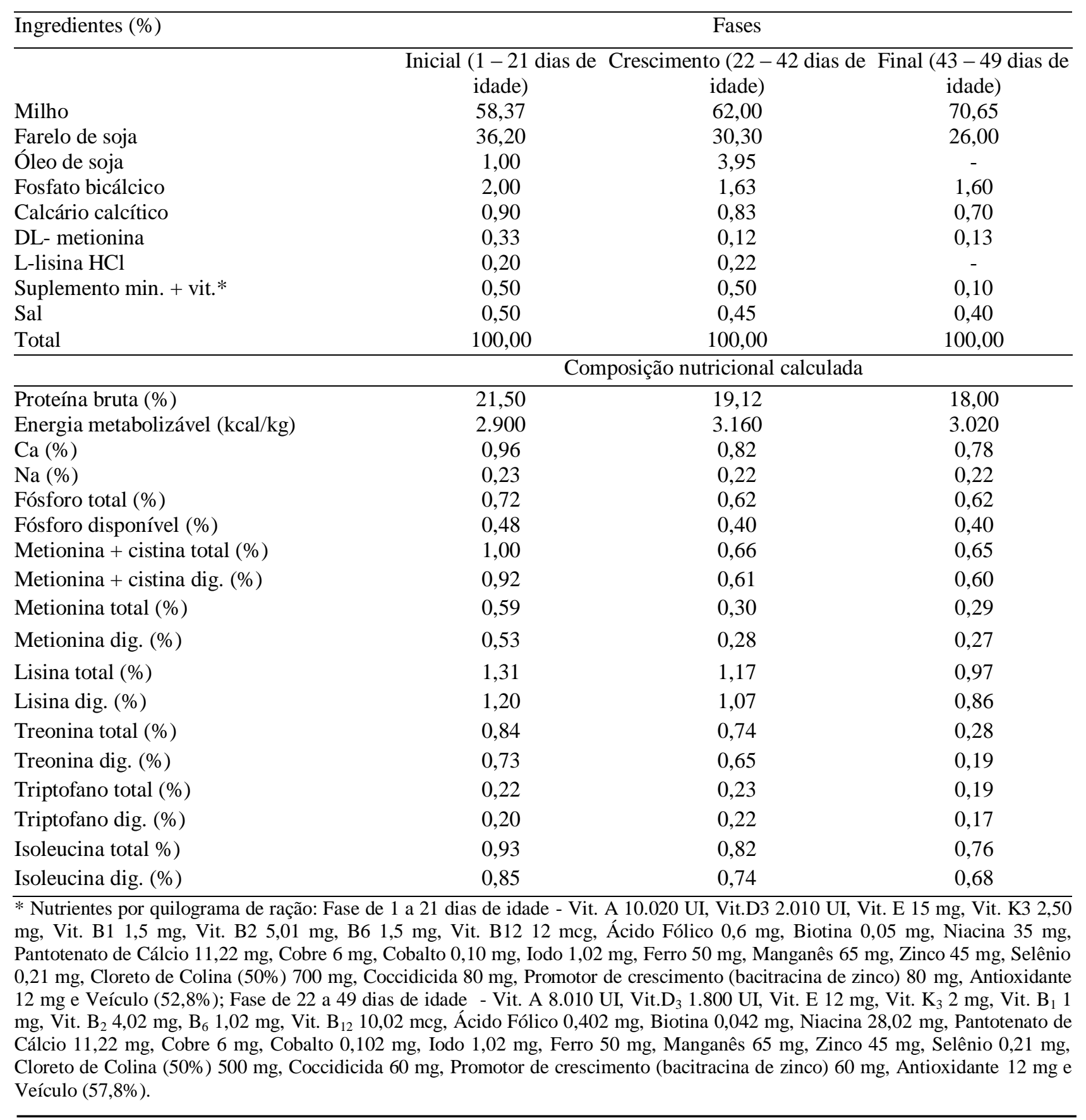


O método utilizado foi o de coleta total de excretas. O ensaio teve duração de seis dias, do $35^{\circ}$ ao $40^{\circ}$ dia do experimento, com três dias de adaptação e três dias de coleta de excretas. Foi adicionado $0,5 \%$ de óxido férrico em todas as rações, no primeiro e no último dia, como marcador do início e do término da coleta das excretas. A água com a adição de silício e a ração, foram fornecidas à vontade durante todo o período experimental.

As excretas coletadas foram armazenadas em congelador a $-10^{\circ} \mathrm{C}$ até o final do período de coleta, quando então, foram descongeladas, devidamente homogeneizadas por repetição, pesadas e colocadas em estufa ventilada por 72 horas a $55^{\circ} \mathrm{C}$, para ser efetuada a pré-secagem. Posteriormente, foram expostas ao ar, por 2 horas, para entrar em equilíbrio com a temperatura e umidade ambiente, e em seguida, foram pesadas, moídas e acondicionadas em placa de petri para as análises posteriores.

Foram anotadas as quantidades de rações consumidas e de excretas produzidas. As análises laboratoriais de matéria seca, fósforo, cálcio e nitrogênio das rações e das excretas foram feitas pelos métodos descritos por Silva \& Queiroz (2002). Os parâmetros avaliados foram: médias de ingestão $(\mathrm{g})$, excreção $(\mathrm{g})$ e retenção de fósforo $(\mathrm{g})$; ingestão $(\mathrm{g})$, excreção $(\mathrm{g})$ e retenção de cálcio $(\mathrm{g})$; e ingestão $(\mathrm{g})$, excreção $(\mathrm{g})$ e retenção de nitrogênio $(\mathrm{g})$.

\section{Análise estatística}

Os dados foram verificados quanto à presença de outliers e testados quanto às pressuposições de normalidade dos erros estudentizados e de homogeneidade de variâncias. Depois de constatada a não violação dessas pressuposições, os dados foram submetidos à análise de variância $(5 \%)$ através do procedimento General Linear Model (GLM) do programa SAS $^{\circledR}$ (SAS Institute, 2002). Havendo diferença significativa entre médias pelo teste $\mathrm{F}$ da análise de variância, foram utilizados os modelos de regressão: linear, quadrático e cúbico, quanto aos níveis de silício sobre as variáveis estudadas.

\section{RESULTADOS E DISCUSSÃO}

De acordo com os resultados obtidos durante o período de 1 a 49 dias de idade das aves, os diferentes níveis de silício adicionados à água de bebida não promoveram efeito significativo nos parâmetros de desempenho (Tabela 2).

De modo semelhante a estes resultados, Carlisle (1981), ao trabalhar com a suplementação de silício em pintainhos, não observou efeito significativo sobre as características de crescimento das aves. Porém, em 1972, o mesmo autor ao trabalhar com frangos alimentados com uma ração purificada em aminoácido e baixa inclusão de silício observou o retardo de crescimento e desenvolvimento das aves, entre as $2^{\text {as }} \mathrm{e}$ $3^{\text {as }}$ semanas de vida, ou seja, $50 \%$ menor quando comparados aos frangos alimentados com a mesma ração suplementada com silício.

A suplementação com silício pode aumentar o teor mineral ósseo e a densidade mineral óssea (CARLISLE, 1970, 1981; CLEMENTI et al., 2001). O silício tem sido relatado como um importante componente na formação óssea e a sua deficiência influencia negativamente o desenvolvimento do esqueleto (SCHWARZ e MILNE, 1972). No presente estudo, esse efeito sobre a mineralização óssea, não afetou de maneira significativa os parâmetros de desempenho das aves.

$\mathrm{Na}$ avaliação dos parâmetros de rendimento de carcaça e de cortes foi observado efeito quadrático para o rendimento de coxa + sobrecoxa das aves (Tabela 3 ). Através da equação apresentada $\left(\mathrm{y}=-1,39 \mathrm{x}^{2}+2.283 \mathrm{x}\right.$ + 27.936) (Figura 1), estimou-se o nível de silício em $0,82 \mathrm{mg}$ de produto/100 $\mathrm{kg}$ de peso/dia como ideal para obter-se o valor máximo de rendimento de coxa + sobrecoxa que foi de $28,87 \%$.

Não foram encontrados na literatura estudos avaliando o efeito da suplementação de silício sobre o rendimento de carcaça e de cortes. Portanto, é importante o incentivo de pesquisas relacionadas aos aspectos nutricionais desse elemento dentro da criação animal.

Tabela 2 - Médias das características de desempenho de frangos de corte machos na fase de 1 a 49 dias de idade, que receberam silício na água de bebida.

\begin{tabular}{lcccc}
\hline $\begin{array}{l}\text { Níveis do produto com } \\
\text { silício }(\mathrm{mg} / 100 \mathrm{~kg} \text { de peso } \\
\text { vivo/dia) }\end{array}$ & $\begin{array}{c}\text { Ganho de peso } \\
(\mathrm{g})\end{array}$ & $\begin{array}{c}\text { Consumo de ração } \\
(\mathrm{g})\end{array}$ & $\begin{array}{c}\text { Conversão alimentar } \\
(\mathrm{g} / \mathrm{g})\end{array}$ & $\begin{array}{c}\text { Viabilidade criatória } \\
(\%)\end{array}$ \\
\hline 0mg & 3168,14 & 5806,85 & 1,83 & 97,30 \\
$0,5 \mathrm{mg}$ & 3160,34 & 5787,77 & 1,83 & 99,55 \\
$1,0 \mathrm{mg}$ & 3199,72 & 5896,34 & 1,86 & 94,95 \\
$1,5 \mathrm{mg}$ & 3151,60 & 5769,40 & 1,83 & 96,69 \\
\hline CV(\%) & 2,54 & 2,83 & 1,28 & 2,95 \\
\hline Efeitos de regressão & $\mathrm{NS}$ & $\mathrm{NS}$ & $\mathrm{NS}$ & $\mathrm{NS}$ \\
\hline
\end{tabular}

NS = não significativo. 
Tabela 3 - Médias das características de carcaça e gordura abdominal, de frangos de corte machos aos 49 dias de idade, que receberam silício na água de bebida.

\begin{tabular}{lcccccc}
\hline $\begin{array}{l}\text { Níveis do produto com } \\
\text { silício (mg/100kg de peso } \\
\text { vivo/dia) }\end{array}$ & ${ }^{\mathrm{I}} \mathrm{RC}$ & $\mathrm{RP}$ & $\mathrm{RC}+\mathrm{SC}$ & $\mathrm{RA}$ & $\mathrm{RD}$ & $\mathrm{GA}$ \\
\cline { 2 - 7 } & & & & & & \\
\hline $\mathrm{mg}$ & 75,19 & 39,39 & 27,91 & 10,13 & 21,99 & 1,50 \\
$0,5 \mathrm{mg}$ & 74,02 & 39,10 & 28,81 & 10,07 & 21,57 & 1,31 \\
$1,0 \mathrm{mg}$ & 75,20 & 38,70 & 28,75 & 9,95 & 22,01 & 1,47 \\
$1,5 \mathrm{mg}$ & 75,30 & 38,87 & 28,26 & 10,16 & 21,58 & 1,33 \\
\hline $\mathrm{CV}(\%)$ & 2,51 & 4,47 & 4,13 & 6,30 & 5,04 & 41,26 \\
\hline Efeitos de regressão & $\mathrm{NS}$ & $\mathrm{NS}$ & Quadrática & $\mathrm{NS}$ & $\mathrm{NS}$ & $\mathrm{NS}$
\end{tabular}

$\mathrm{NS}$ = não significativo, ${ }^{\mathrm{R} C}=$ rendimento de carcaça, $\mathrm{RP}=$ rendimento de peito, $\mathrm{RC}+\mathrm{SC}=$ rendimento de coxa+sobrecoxa, $\mathrm{RA}=$ rendimento de asa, $\mathrm{RD}=$ rendimento de dorso, $\mathrm{GA}=$ gordura abdominal.

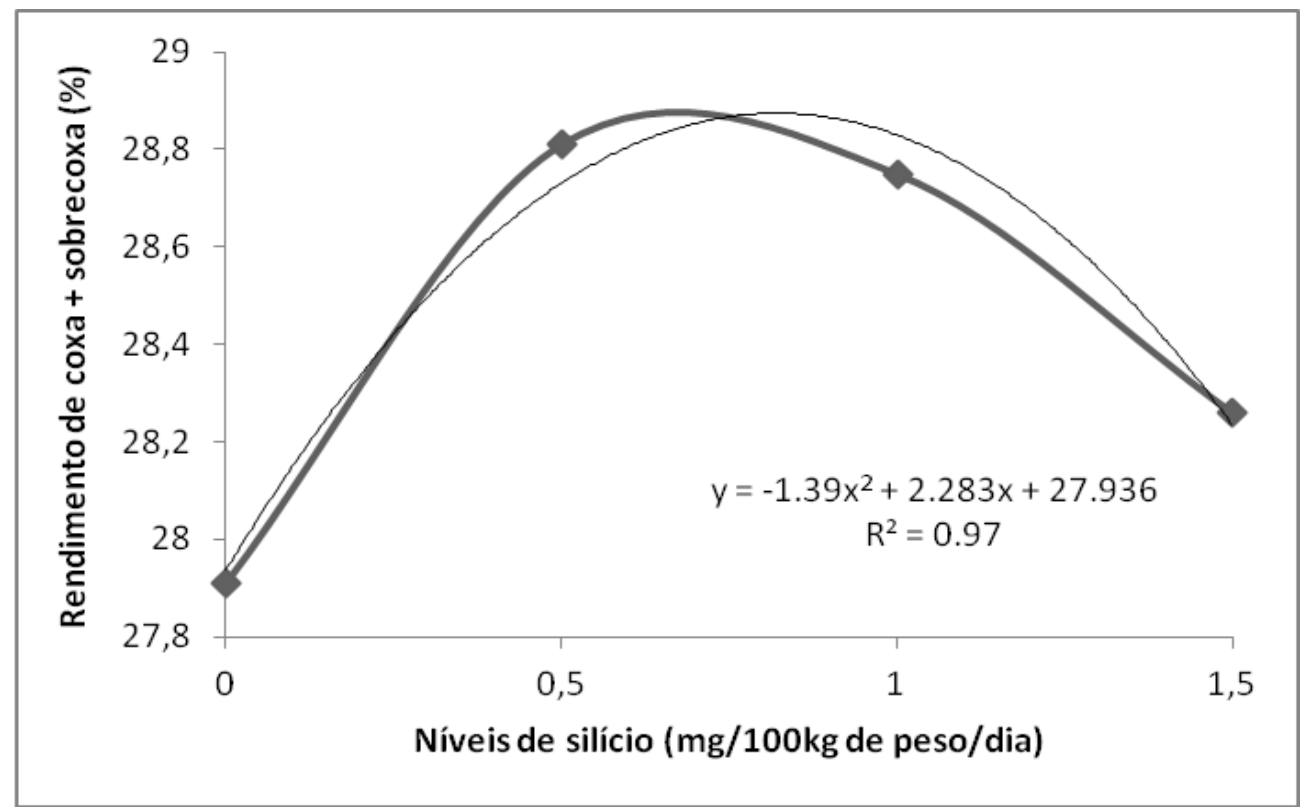

Figura 1 - Efeito de diferentes níveis do produto com silício na água de bebida sobre o rendimento de coxa+sobrecoxa de frangos de corte aos 49 dias de idade.

Os grupos de ácidos graxos (monoinsaturados, poliinsaturados, insaturados e saturados) avaliados no músculo peitoral de frangos de corte não foram influenciados significativamente pelos diferentes níveis de silício suplementados na água de bebida das aves aos 49 dias de idade (Tabela 4). Porém, ao analisar-se separadamente, todos os ácidos graxos (Tabela 5), observou-se efeito linear para os seguintes ácidos graxos: vacênico, $\gamma$-linolênico e araquidico e palmítico, enquanto que para os ácidos graxos mirístico, miristoleico, palmitoleico, eicosadienoico foi observado efeito quadrático (Figuras 2 e 3).

A atual demanda dos consumidores por alimento de melhor qualidade tem revelado grande interesse em modificar a composição lipídica da carne de frango.
Os ácidos graxos saturados e monoinsaturados encontrados no músculo peitoral dependem de fatores como: presença na ração, de sua oxidação nos tecidos e da síntese pelo fígado (NIR et al., 1988). No entanto, no presente estudo, o silício foi fornecido via água de bebida, portanto, a mesma ração experimental foi fornecida para todas as aves. No entanto, Olomu e Baracos (1991) sugeriram que determinados percentuais dos ácidos graxos saturados e monoinsaturados são necessários para a deposição tecidual, sendo, portanto, sua deposição alcançada pela síntese de novo ao invés de ser regulada pela ração. Wood e Enser (1997), da mesma forma, afirmaram que a maioria dos ácidos graxos saturados e monoinsaturados é obrigatoriamente sintetizado, e sua concentração é pouco influenciada pela ração. 
Tabela 4 - Médias das características do perfil de ácidos graxos do músculo peitoral de frangos de corte machos aos 49 dias de idade, que receberam silício na água de bebida.

\begin{tabular}{lcccc}
\hline $\begin{array}{l}\text { Níveis do produto com } \\
\text { silício (mg/100kg de peso } \\
\text { vivo/dia) }\end{array}$ & Monoinsaturado & Poliinsaturado & Insaturado & Saturado \\
\cline { 2 - 5 } 0mg & & $(\%)$ & \\
$0,5 \mathrm{mg}$ & 34,36 & 34,97 & 0,12 & 29,27 \\
$1,0 \mathrm{mg}$ & 31,99 & 36,70 & 0,17 & 29,68 \\
$1,5 \mathrm{mg}$ & 32,58 & 35,09 & 0,17 & 30,58 \\
\hline CV(\%) & 33,99 & 34,67 & 0,15 & 30,12 \\
\hline Efeito de regressão & 8,27 & 6,68 & 2,51 & 13,83 \\
\hline NS = não significativo. & $\mathrm{NS}$ & $\mathrm{NS}$ & $\mathrm{NS}$ & $\mathrm{NS}$ \\
\hline
\end{tabular}

Tabela 5 - Médias das características do perfil de ácidos graxos do músculo peitoral de frangos de corte machos aos 49 dias de idade, que receberam silício na água de bebida.

\begin{tabular}{|c|c|c|c|c|c|c|}
\hline \multirow[t]{2}{*}{ Ácidos graxos (\%) } & \multicolumn{6}{|c|}{$\begin{array}{l}\text { Níveis do produto com silício } \\
\text { (mg/100kg de peso vivo/dia) }\end{array}$} \\
\hline & $0 \mathrm{mg}$ & $0,5 \mathrm{mg}$ & $1,0 \mathrm{mg}$ & $1,5 \mathrm{mg}$ & $\mathrm{CV}(\%)$ & Efeitos de regressão \\
\hline Mirístico & 0,41 & 0,36 & 0,41 & 0,50 & 9,74 & Quadrática \\
\hline Miristoleico & 0,08 & 0,06 & 0,07 & 0,10 & 14,91 & Quadrática \\
\hline Pentadecanoico & 0,09 & 0,08 & 0,09 & 0,08 & 10,50 & NS \\
\hline Palmítico & 21,31 & 20,81 & 21,61 & 22,00 & 1,75 & Linear \\
\hline Palmitoleico & 3,01 & 2,13 & 2,47 & 3,28 & 22,03 & Quadrática \\
\hline Heptadecanoico & 0,13 & 0,16 & 0,13 & 0,15 & 16,13 & NS \\
\hline Heptadecenoico & 0,05 & 0,07 & 0,05 & 0,05 & 20,33 & NS \\
\hline Esteárico & 7,28 & 8,21 & 8,27 & 7,31 & 10,43 & NS \\
\hline Oléico & 28,97 & 27,41 & 27,74 & 28,49 & 7,31 & NS \\
\hline Vacênico & 2,03 & 2,09 & 1,93 & 1,80 & 7,05 & Linear \\
\hline Linoleico & 27,42 & 27,55 & 26,71 & 27,79 & 5,87 & NS \\
\hline$\gamma$-linolênico & 0,20 & 0,21 & 0,26 & 0,29 & 21,81 & Linear \\
\hline$\alpha$-linolênico & 1,33 & 1,35 & 1,35 & 1,46 & 9,51 & NS \\
\hline Araquidico & 0,07 & 0,07 & 0,08 & 0,08 & 6,90 & Linear \\
\hline Eicosenoico & 0,23 & 0,25 & 0,31 & 0,27 & 7,93 & NS \\
\hline Eicosadienoico & 1,05 & 1,03 & 1,02 & 0,67 & 7,58 & Quadrática \\
\hline Eicosatrienoico & 0,67 & 0,65 & 0,81 & 0,61 & 14,52 & NS \\
\hline Eicosatrienoico & 3,85 & 5,27 & 4,49 & 3,51 & 30,81 & NS \\
\hline Araquidônio & 0,05 & 0,07 & 0,08 & 0,06 & 33,95 & NS \\
\hline Eicosapentaenoico & 0,12 & 0,17 & 0,17 & 0,15 & 18,83 & NS \\
\hline Docosahexaenoico & 0,41 & 0,58 & 0,37 & 0,29 & 38,30 & NS \\
\hline
\end{tabular}

NS = não significativo. 'mirístico: $0,14 \mathrm{x}^{2}-0,146 \mathrm{x}+0,407\left(\mathrm{R}^{2}=0,98\right)$; miristoleico: $0,05 \mathrm{x}^{2}-0,061 \mathrm{x}+0,0795\left(\mathrm{R}^{2}=0,97\right)$; palmítico: $0,89 \mathrm{x}^{2}-$ $0,761 x+21,224 \quad\left(R^{2}=0,81\right)$; palmitoleico: $1,69 x^{2}-2,305 x+2,9725 \quad\left(R^{2}=0,97\right)$; vacênico: $-0,17 x+2,09 \quad\left(R^{2}=0,95\right)$; $\gamma$-linolênico: $0,064 x+0,192\left(R^{2}=0,95\right)$; araquidico: $0,008 x+0,069\left(R^{2}=0,80\right)$; eicosadienico: $-0,33 x^{2}+0,265 x+1,0325\left(R^{2}=0,94\right)$. 


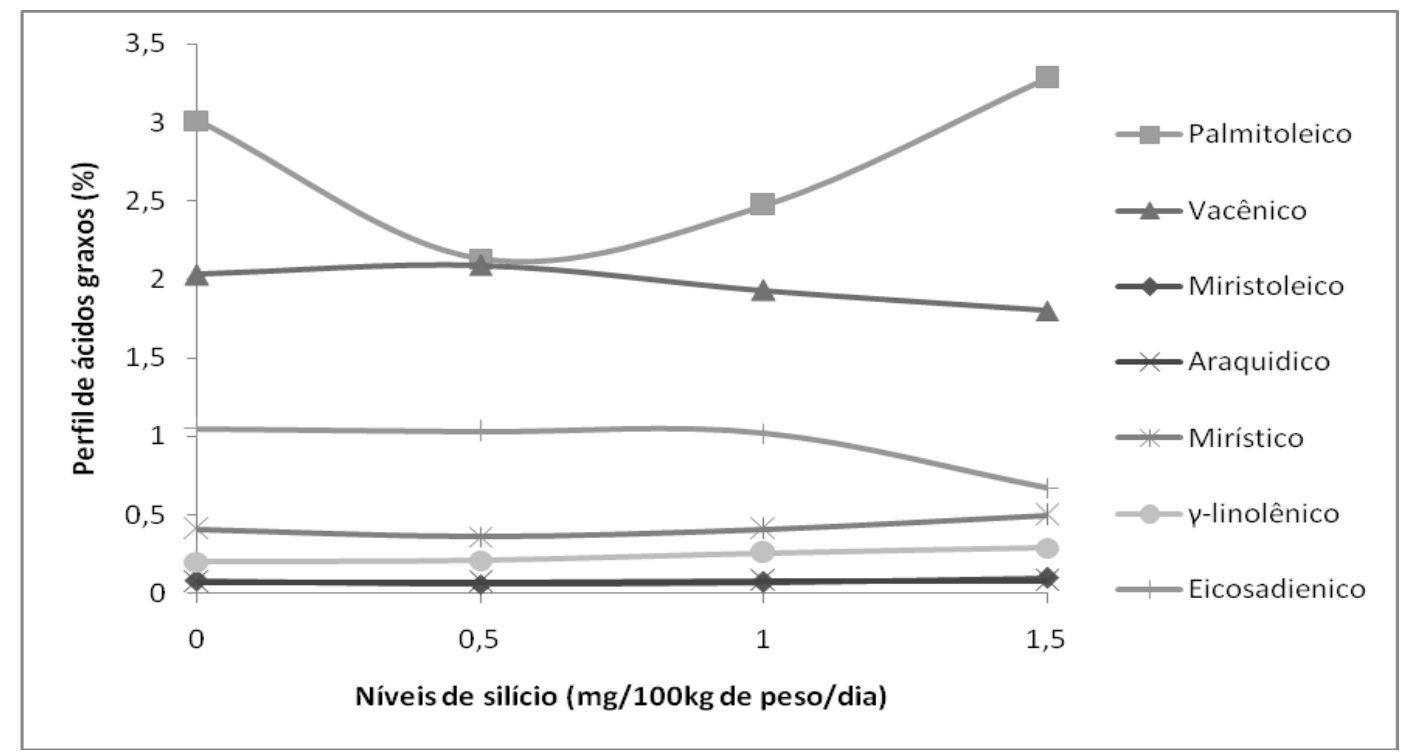

Figura 2 - Efeito de diferentes níveis do produto com silício na água de bebida sobre o perfil de ácidos graxos do musculo peitoral de frangos de corte aos 49 dias de idade.

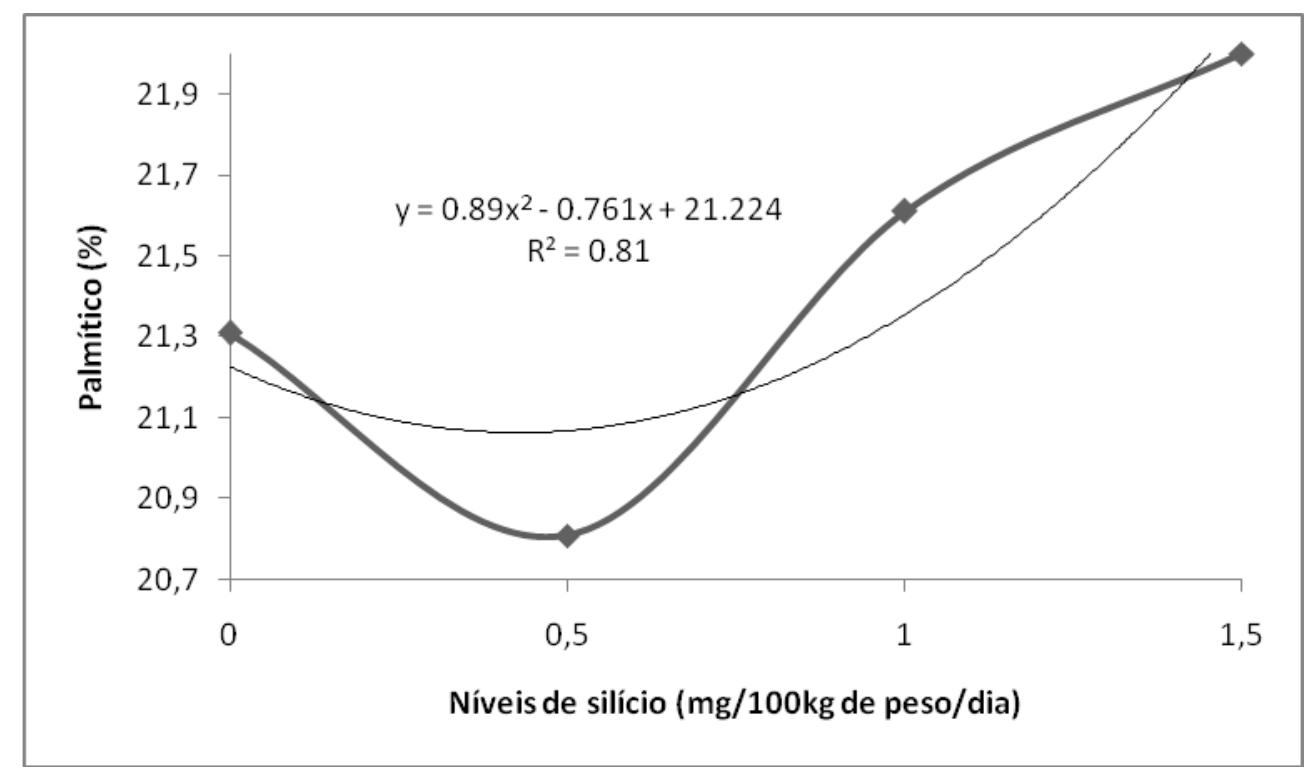

Figura 3 - Efeito de diferentes níveis do produto com silício na água de bebida sobre o ácido graxo palmítico do musculo peitoral de frangos de corte aos 49 dias de idade.

Pouco se sabe da influencia do silício sobre a deposição de ácidos graxos no músculo peitoral, sendo um trabalho inédito onde se buscou avaliar seus efeitos sobre várias características, observou-se no estudo que o silício influencia a deposição desses ácidos. Sendo assim mais estudos sobre este mineral devem ser realizados e qual o seu papel fisiológico na deposição de ácidos graxos no músculo peitoral.

Os dados mostram que com o maior nível de silício na água de bebida, houve um aumento na percentagem de ácidos mono e poliinsaturados $(\gamma-$ linolênico, araquidico, miristoleico e palmitoleico). A presença do ácido $\gamma$-linolênico no organismo, por não ser sintetizado pelas aves, depende de seu fornecimento na ração ou de seu nível de oxidação nos tecidos (MARTINS et al., 2003). Os ácidos graxos de cadeia longa, como o ácido $\gamma$-linolênico e derivados, têm sido associados com a redução das doenças coronarianas.
Ocorre que essas substâncias atuam na dinâmica da coagulação do sangue prevenindo a formação de ateromas (FERREIRA, 1999). Portanto, a suplementação de silício alterou o perfil de ácidos graxos no músculo peitoral de frangos de corte, fato este difícil de ser explicado, já que a composição de ácidos graxos neste tecido pode ser manipulada mediante mudança na composição de ácidos graxos da ração (SCAIFE et al.,1994; HRDINKA et al., 1996), mostrando assim que, provavelmente, existem outras influências metabólicas no depósito destes ácidos graxos.

Os diferentes níveis de silício não influenciaram de maneira significativa os parâmetros avaliados durante o ensaio de metabolismo das aves (médias de ingestão $(\mathrm{g})$, excreção $(\mathrm{g})$ e retenção $(\mathrm{g})$ de fósforo, de cálcio e de nitrogênio) (Tabela 6). 
Tabela 6 - Médias das características do ensaio de metabolismo de frangos de corte machos aos 35 dias de idade, que receberam silício na água de bebida.

\begin{tabular}{lccccccccc}
\hline $\begin{array}{l}\text { Níveis do produto com } \\
\text { silício (mg/100kg de peso } \\
\text { vivo/dia) }\end{array}$ & ${ }^{\mathrm{I}} \mathrm{IP}$ & $\mathrm{EP}$ & $\mathrm{RP}$ & $\mathrm{ICa}$ & $\mathrm{ECa}$ & $\mathrm{RCa}$ & $\mathrm{IN}$ & $\mathrm{EN}$ & $\mathrm{RN}$ \\
\cline { 2 - 10 } & & & & & $(\mathrm{g})$ & & & & \\
\hline 0mg & 11,08 & 2,52 & 8,56 & 14,67 & 5,13 & 9,53 & 52,31 & 9,12 & 43,19 \\
$0,5 \mathrm{mg}$ & 10,88 & 2,87 & 8,01 & 14,40 & 4,84 & 9,56 & 51,36 & 9,43 & 41,93 \\
$1,0 \mathrm{mg}$ & 10,50 & 2,67 & 7,83 & 13,90 & 4,71 & 9,19 & 49,58 & 9,17 & 40,41 \\
$1,5 \mathrm{mg}$ & 10,40 & 2,14 & 8,26 & 13,77 & 4,97 & 8,80 & 49,10 & 9,89 & 39,23 \\
\hline CV(\%) & 5,94 & 23,69 & 15,58 & 5,94 & 17,64 & 17,83 & 5,94 & 18,67 & 11,14 \\
\hline Efeitos de regressão & NS & NS & NS & NS & NS & NS & NS & NS & NS
\end{tabular}

$\mathrm{NS}$ = não significativo. ${ }^{1} \mathrm{IP}$ = ingestão de fósforo, $\mathrm{EP}=$ excreção de fósforo, $\mathrm{RP}$ = retenção de fósforo, $\mathrm{ICa}=$ ingestão de cálcio, ECa $=$ excreção de cálcio, $\mathrm{RCa}=$ retenção de cálcio, $\mathrm{IN}=$ ingestão de nitrogênio, $\mathrm{EN}=$ excreção de nitrogênio, $\mathrm{RN}=$ retenção de nitrogênio.

Estudos têm mostrado que a temperatura ambiente elevada influencia a retenção e a excreção de minerais em aves (SMITH e TEETER, 1987; SAHIN e KUCUK, 2003). O estudo de El Husseiny e Creger (1981) mostra que os frangos criados sob estresse ambiental tiveram menores taxas de $\mathrm{Ca}, \mathrm{Cu}, \mathrm{Fe}, \mathrm{K}, \mathrm{Mg}$, $\mathrm{Mn}, \mathrm{Na}, \mathrm{P}, \mathrm{Zn}$ nas excretas e retenção no organismo. Além disso, o estresse por calor faz com que o fígado acumule minerais, diminuindo assim, ainda mais, a concentração de mineral no plasma, e aumentando potencialmente a deficiência de minerais, disponíveis, o que leva ao aumento da exigência de minerais na dieta (SAHIN et al., 2006).

Sahin et al. (2006) relatam que com a suplementação de arginina+silício+inositol, melhorou se a digestibilidade de proteína e cinzas em aves criadas em altas temperaturas ambientes, além disso houve queda na excreção de $\mathrm{Ca}, \mathrm{P}, \mathrm{Mg}, \mathrm{Mn}$ em aves criadas sob estresse calórico, dados estes semelhantes aos de Carlisle, 1972; Schwarz \& Milne, 1972; Fiore et al., 2000 e Clementi et al., 2001. No entanto, no presente estudo, as aves foram criadas dentro de sua zona termoneutra durante todo o período, não sendo possível a avaliação da expressão no metabolismo dos minerais estudados com a suplementação de silício via água de bebida.

\section{CONCLUSÃO}

A suplementação de silício via água de bebida modifica o perfil de ácidos graxos no músculo peitoral de frangos de corte, bem como o rendimento de coxa + sobrecoxa, podendo, portanto, ser uma ferramenta importante para ser utilizada na nutrição das aves durante o período de criação.

\section{REFERENCIAS}

AVISITE. Ubabef defende instalação de marco regulatório para integração. Disponível em: <http://avisite.com.br/clipping/index.php?codclipping= 18922>. Acessado em 25 de janeiro de 2013.
CARLISLE, E. M. A requirement in bone formation independent of vitamin $D_{1}$. Science, v.33, p.27-34, 1981.

CARLISLE, E. M. Silicon as an essential element for the chick. Science, v.178, p.619-621. 1972.

CARLISLE, E. M. Silicon: a possible factor in bone calcification. Science, v.167, p.279-280, 1970.

ClEMENTI, G.; FIORE, C. E.; MARGANO, N. G. Role of soy diet and L-arginine in cyclosporine Ainduced osteopenia in rats. Pharmacolology and Toxicology, v.88, p.16-19, 2001.

EL HUSSEINY, O.; CREGER, C. R. Effect of ambient temperature on mineral retention and balance of the broiler chicks. Poultry Science, 60(Suppl. 1): 1651(Abstr.). 1981.

ELLIOT, M. A.; EDWARDS, H. M. Effect of dietary silicon on growth and skeletal development in chickens. Journal of Nutrition, v.121, n.2, p.201, 1991.

FERREIRA, J. M.; BRAGA, M. S.; SOUSA, R. V.; CAMPOS, E. J.; VIEIRA, E. C. Composição em ácidos graxos da gordura na carcaça de frangos de corte sob dietas com diferentes fontes de energia. Arquivos Brasileiros de Medicina Veterinária e Zootecnia, v.51, p.201-206, 1999.

FIORE, C. E.; PENNISI, P.; CUTULI, V. M.; PRATO, A.; MESSINA, R.; CLEMENTI, G. L-Arginine prevents bone loss and bone collagen breakdown in cyclosporin A-treated rats. European Journal of Pharmacology, v.408, p.323-326, 2000.

HRDINKA, C.; ZOLLITSCH, W.; KNAUS, W.; LETTTTNER, F. Effects of dietary fatty acids pattern on melting point and composition of adipose tissues and intramuscular fat of broiler carcasses. Poultry Science, v.75, p.208-215, 1996. 
HULAN, H. W.; ACKMAN, R. G.; RATNAYAKE, W. M. N.; PROUDFOOT, F. G. Omega-3 fatty acid levels and general performance of commercial broilers fed practical levels of redfish meal. Poultry Science, v.68, p.153-162, 1989.

MARTINS, R. T.; CASCABULHO, A. R.; BAIÃO, N. C.; AFONSO, R. J. G. F. Efeito do tipo de óleo de soja na composição em ácidos graxos da carcaça de frangos de corte. Arquivos Brasileiros de Medicina Veterinária e Zootecnia, v.55, p.92-98, 2003.

NIR, I.; NITSAN, Z.; KEREN-ZVI, S. Fat deposition in birds. In: LECLEECQ, B.; WHITE, C. (Eds.). Leaness in domestic birds. London: Butherworths, 1988. p.141-174.

OLOMU, J. M.; BARACOS, V. E. Influence of dietary flaxseed oil on the performance, muscle protein deposition, and fatty acid composition of broiler chicks. Poultry Science, v.70, p.1403-1411, 1991.

ROSTAGNO, H. S.; ALBINO, L. F. T.; DONZELE, J. L.; GOMES, P. C.; OLIVEIRA, R. F. de; LOPES, D. C.; FERREIRA, A. S.; BARRETO, S. L. de T. Tabelas brasileiras para aves e suínos: composição de alimentos e exigências nutricionais. 3.ed. Viçosa: UFV, 2005.

SAHIN, K.; KUCUK, O. Zinc supplementation alleviates heat stress in laying Japanese quail. Journal of Nutrition, v.133, p.2808-2811, 2003a.

SAHIN, K.; ONDERCI, M.; SAHIN, N.; BALCI, T. A.; GURSU, M. F.; JUTURU, V.; KUCUK, O. Dietary arginine silicate inositol complex improves bone mineralization in quail. Poultry Science, v.85, p.486-492, 2006.
SAS Institute. SAS ${ }^{\circledR}$ user' guide: statistics. Cary, NC, 2002.

SCAIFE, J. R.; MOYO, J.; GALBRAITH, H.; MICHIE, W.; CAMPBELL V. Effect o different dietary supplemental fats and oils on the tissue fatty acid composition and growth of female broilers. British Poultry Science, v.35, p.107-118, 1994.

SCHWARZ, K.; MILNE, D. B. Growth promoting effects of silicon in rats. Nature, v.239, p.333-334, 1972.

SILVA, D. J.; QUEIROZ, A.C. Análise de alimentos: métodos químicos e biológicos. 3.ed. Viçosa: UFV, 2002.

SMITH, M. O.; TEETER, R. G. Potassium balance of the 5 to 8 -week-old broiler exposed to constant heat or cycling high temperature stress and the effects of supplemental potassium chloride on body weight gain and feed efficiency. Poultry Science, v.66, p.487-492, 1987.

WOOD, J. D.; ENSER, M. Factors influencing fatty acids in meat and the role of antioxidants in improving meat quality. British Poultry Science, 78(Suppl.1): p.49-60, 1997. 